\title{
Detection of damage in a beam like structure using Wavelet Analysis
}

[Divya Vani B, B Prakruthi Gowd, Dr. Manjunath N Hegde]

\begin{abstract}
Damage in a structure will adversely affect its current and future performance. Most often the extent and location of damage can be determined through visual inspection. However, in many cases this may not be feasible at initial or later stages. Structural damages may cause local changes in one or more parameters like stiffness, mass and damping that affects the dynamic behaviour of the structure. Modal parameters are sensitive indicators of structural damage. In this paper, the wavelet transform (both continuous and discrete) has been used to detect, locate and find the severity of the damage in a beams like structure which does not require the knowledge of the undamaged state.
\end{abstract}

Keywords-Damage Detection, wavelet transform, wavelet coefficients.

\section{Introduction}

Damage can be defined as the changes introduced into a system that adversely affects its current or future performance. Implicit in this definition is the concept that damage is not meaningful without a comparison between two different states of the system, one of which is assumed to represent the initial and often undamaged state and other being the damaged state. The condition of a normal structure or an aging structure is monitored to detect damages that could possibly lead to the failure of the structure. The interest in the ability to monitor a structure and detect damage at the earliest possible stage is of great importance in order to avoid catastrophic effects.

A signal is a representation of a physical process. Signals are perceived by the sensors which characterizes them. It implies the physical state of process indirectly. People from every field of technology might deal with signals on so many occasions. This has broadened the application of signal processing. Based on signal processing techniques, monitoring and interpreting changes on the structural dynamic measurements can be considered as a quite promising approach for damage identification and health monitoring. A brief over view of the literature is as below:

B Prakruthi Gowd

Assistant Professor, Vidya Jyothi Institute of Technology

Hyderabad, India

Divya Vani B

Assistant Professor, Vidya Jyothi Institute of Technology

Hyderabad, India

Dr. Manjunath N. Hegde (Dr. M. N. Hegde)

Dean-Academic \& Professor, Dr. Ambedkar Institute of Technology

Bengaluru, India
Surace and Ruotolo [1] have used the Wavelet Transform to depict how the simulated vibration response signal of a cracked beam can be used to identify the presence of cracks. Wang and McFadden [2] had used the Wavelet Transform to study actual gearbox vibration signals in the time domain and thereby find their local behavior and their features. It was shown that damage of the gear could be correlated to features in the wavelet domain. Also, Staszewski and Tomlinson [3] used visual inspection of the modulus and phase of the Wavelet Transform to identify the fault in a spur gear. Liew and Wang [4] were able to analyze the Wavelet Transform along the length of the beam by using the numerical solution for the deflection of the beam. Wang and Deng [5] discussed the application of the DWT of spatially distributed structural response measurements. Alkhalidy et al. [6] used the Wavelet Transform to detect the fatigue damage in structures, modeling that damage as a random impulse in the input signal. Hou et al. [7] showed that structural damage can be identified by details at level 1 from the DWT of the response signal, with the spike at the details at level 1 indicating the instant in time at which damage occurs. Hera et al. [8] applied the DWT approach to the FEM model of the ASCE Structural Health Monitoring Benchmark Study.

In the current investigation a Signal processing tool called Wavelet Analysis/Transform technique has been proposed for structural damage identification. The approach adopted here utilizes the vibration parameters of the beam structure (i.e., the Mode shape) and Wavelet Analysis has been carried out on these mode shapes to predict the Location and severity of the crack present in the system.

\section{Development of Models and Extraction of Modal Properties Using Ansys}

\section{A. Methodology}

A single crack identification algorithm using Wavelet Transform has been studied. The wavelet approach uses the vibration response of the structure obtained from ANSYS (i.e., first mode shape) in its analysis. The wavelet transform for crack detection has been designed with one input signal (first mode shape) and output obtained is the wavelet coefficients. Both continuous and discrete wavelet transform has been performed on the input signals. With the help of wavelet analysis existence, location and to some extent the severity of the damage can be detected.

\section{B. Model Specifications, Cases studied}

The geometric and material properties of the structure chosen to present numerical results is a fixed Flat along with the cases studied for the work are given in Table I and Figure 1 shows the Fixed Flat model along with the cross section: 
Proc. of Seventh International Conference On Advances in Civil, Structural and Mechanical Engineering -ACSM 2017 Copyright (C) Institute of Research Engineers and Doctors, USA .All rights reserved.

ISBN: 978-1-63248-135-1 doi: 10.15224/ 978-1-63248-135-1-42

TABLE I. MODEL SPECIFICATIONS

\begin{tabular}{|c|c|}
\hline \multicolumn{2}{|c|}{ Geometric Properties } \\
\hline Length of Flat & $3000 \mathrm{~mm}$ \\
\hline Depth of Flat & $200 \mathrm{~mm}$ \\
\hline Width of Flat & $50 \mathrm{~mm}$ \\
\hline \multicolumn{2}{|c|}{ Material Properties } \\
\hline Young's Modulus & $210 \mathrm{GPa}$ \\
\hline Density & $7850 \mathrm{Kg} / \mathrm{m}^{3}$ \\
\hline Poisson's Ratio & 0.3 \\
\hline
\end{tabular}

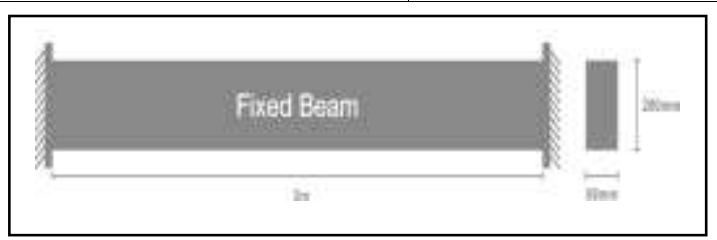

Figure1. Fixed Flat Model

The present investigation is done considering two different cases:

Case A: Crack at same location (@L/16 from one of the fixed end) but with different depth $(10 \mathrm{~mm}, 20 \mathrm{~mm}$ up to $120 \mathrm{~mm}-12$ cases).

Case B: Crack of same depth (120mm form bottom) but at different locations (L/2, L/4 up to $\mathrm{L} / 16$ from one of the fixed end -7 cases).

\section{Modal Analysis}

The inputs for the wavelet transform are the first mode shapes for the different flat models. The mode shape graphs of different models are as shown below in Figure 2 and 3.

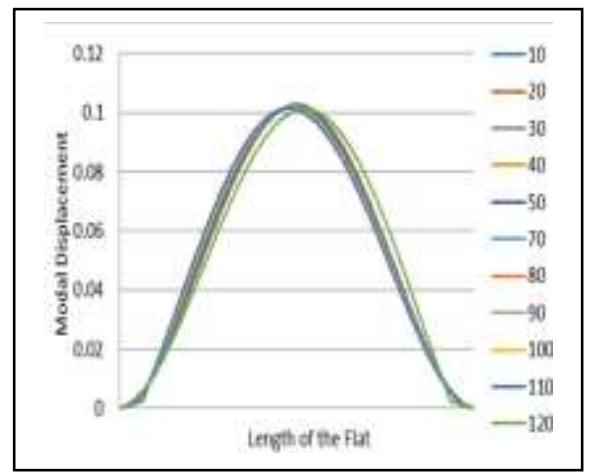

Figure2. First mode shape for undamaged and damaged flats with cracks at same location but with different depths (Case A)

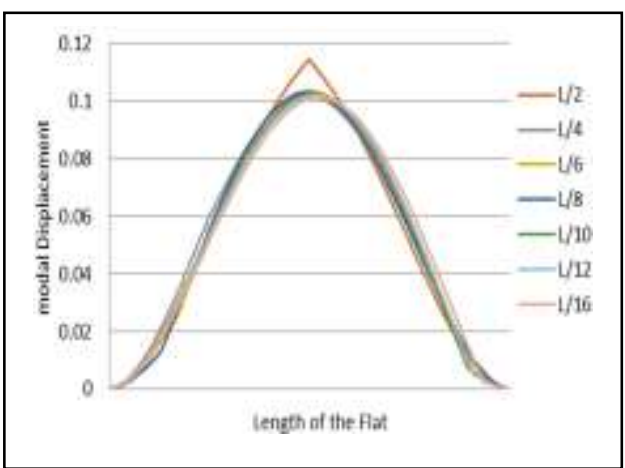

Figure3. First Mode shape for undamaged and damaged flats with crack of same depth but at different locations (Case B).
It can be seen for Figure 2 and Figure 3 that the mode shapes for different cases are almost over lapping with each other. Which indicates that there is no much variation in the mode shape whenever there is a damage introduced in a system. Hence the damage has a very small effect on the mode shapes. This confirms that change in the mode shapes alone cannot be used to detect the damage in a structure, unless the damage is significantly large.

It can be observed that the mode shape is smooth except near the position of the damage where a very small perturbation or discontinuities can be seen. More likely, these perturbations will go undetected if the response is measured experimentally or if a simple visual inspection is conducted. This is where the wavelet analysis performs a very good job in determining these discontinuities.

The ability of wavelets to detect discontinuities in a structural member and in a simple structure is demonstrated with several numerical examples.

\section{Development of Wavelet Analysis Algorithm for Single Crack detection}

Both continuous and discrete wavelet transform have been performed on different mode shapes. During continuous wavelet transform Biorthogonal wavelets (bior 1.1 and bior 2.2) has been used whereas while performing discrete wavelet transform Daubechies Wavelet (db 4) has been used. The above wavelet analysis has been performed in the Wavelet Toolbox available in the Matlab Software.

The screen shot below (Figure 4(a) and Figure 4(b)) shows one example of both continuous and discrete wavelet transform performed in Matlab.

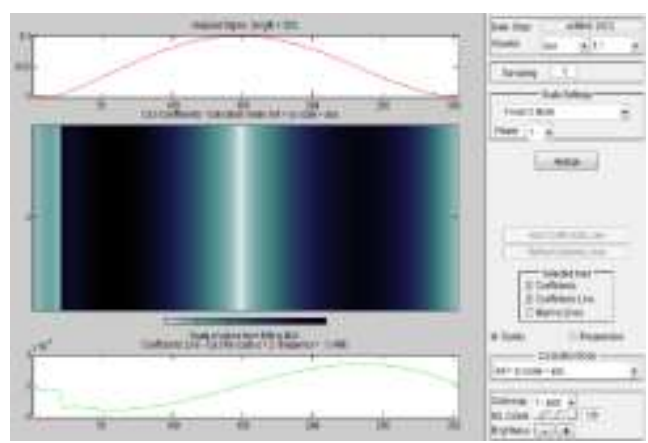

Figure4(a). Continuous wavelet transform performed in Matlab for crack at L/16 location with a crack depth of $80 \mathrm{~mm}$ respectively.

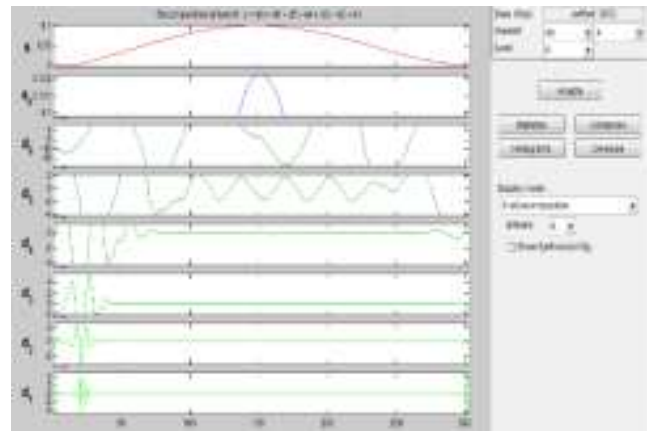

Figure 4(b). Discrete wavelet transform performed in Matlab for crack at $\mathrm{L} / 16$ location with a crack depth of $80 \mathrm{~mm}$ respectively. 
Proc. of Seventh International Conference On Advances in Civil, Structural and Mechanical Engineering -ACSM 2017 Copyright (C) Institute of Research Engineers and Doctors, USA .All rights reserved.

ISBN: 978-1-63248-135-1 doi: 10.15224/ 978-1-63248-135-1-42

The results obtained from the Wavelet Analysis performed for single crack identification are as shown in Figure 5(a), 5(b) and Table II.

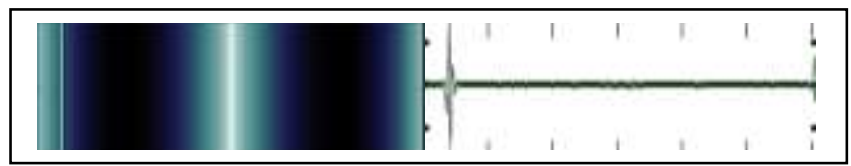

Figure5(a). Continuous and Discrete wavelet transform performed in Matlab for crack at L/16 location with a crack depth of $10 \mathrm{~mm}$. (FB10L16)

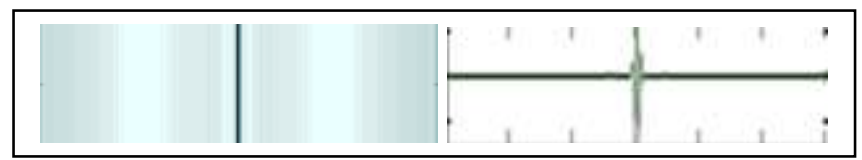

Figure5(b). Continuous and Discrete wavelet transform performed in Matlab for crack at L/16 location with a crack depth of $10 \mathrm{~mm}$. (FB120L2)

TABLE II. RESUlTS OF THE CONTINUOUS AND DisCRETE WAVELET TRANSFORM PERFORMED ON DIFFERENT CASES ALONG WITH THE MAXIMUM AND MINIMUM WAVELET COEFFICIENTS.

\begin{tabular}{|c|c|c|c|c|}
\hline $\begin{array}{c}\text { For } \\
\text { different } \\
\text { depths and } \\
\text { different } \\
\text { locations of } \\
\text { Cracks }\end{array}$ & \multicolumn{2}{|c|}{$\begin{array}{c}\text { Maximum Wavelet } \\
\text { Coefficient }\end{array}$} & \multicolumn{2}{c|}{$\begin{array}{c}\text { Minimum Wavelet } \\
\text { Coefficient }\end{array}$} \\
\cline { 2 - 5 } & Continuous & Discrete & Continuous & Discrete \\
\hline Undamaged & 0.0018 & 0.5999 & -0.0018 & -0.2406 \\
\hline FB10L16 & $7.3681 \mathrm{e}-4$ & 0.8013 & $-7.3751 \mathrm{e}-4$ & -0.0159 \\
\hline FB20L16 & $7.3468 \mathrm{e}-4$ & 0.8015 & $-7.3822 \mathrm{e}-4$ & -0.0158 \\
\hline FB120L2 & $2.4721 \mathrm{e}-4$ & 0.8015 & $-4.8490 \mathrm{e}-5$ & -0.0180 \\
\hline FB120L4 & $4.9502 \mathrm{e}-5$ & 0.8017 & $-4.8490 \mathrm{e}-5$ & -0.0152 \\
\hline
\end{tabular}

It can be seen from Figure 5(a) and 5(b) that at the location of the crack there is a variation in both continuous wavelet transform plot and discrete wavelet transform plot with which the existence and location of the crack can be easily identified by both the types of wavelet transforms.

In order to determine the depth or intensity of the crack a study on the Maximum and Minimum wavelet coefficients for both continuous and discrete wavelet transform has been made for the Case A models and the results obtained are as shown in Figure 6 (a) and 6 (b); Figure 7 (a) and 7(b).

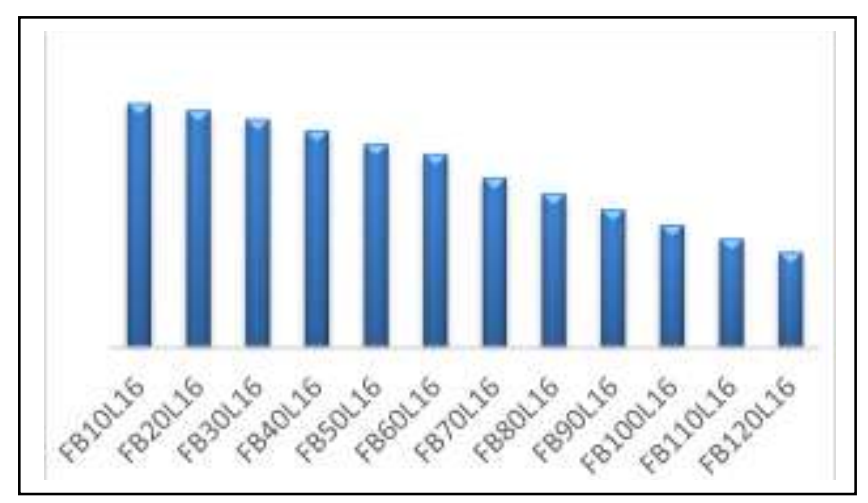

Figure 6(a) Maximum wavelet coefficient for Continuous wavelet transform for cracks at L/16 location with a varying crack depth.

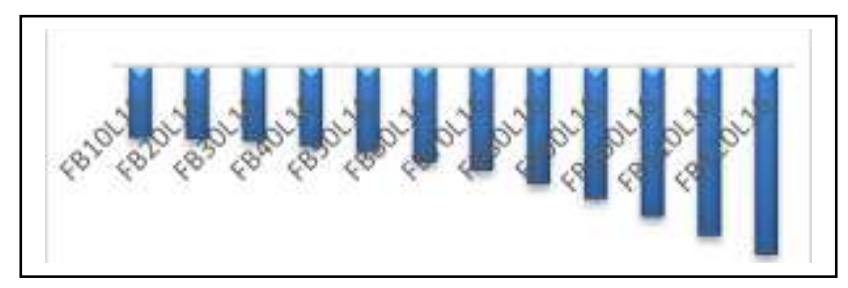

Figure 6(b). Minimum wavelet coefficient for continuous wavelet transform for cracks at L/16 location with a varying crack depth.

It is evident from Fig. 6(a) and (b) that as the depth of the crack increases the maximum and minimum continuous wavelet coefficient also decreases. By knowing the maximum and minimum continuous wavelet coefficient for the undamaged flat the relative depth of the crack may be found out. Thus the above can be effectively used in determining the depth or intensity of the crack.

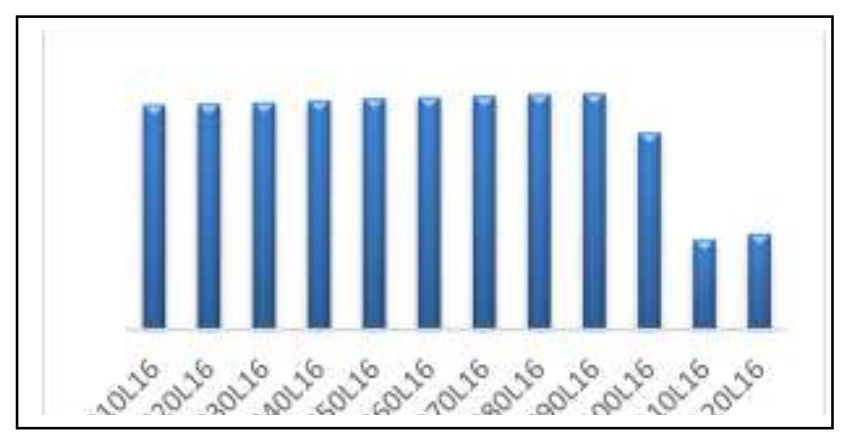

Figgure 7(a) Maximum wavelet coefficient for Discrete wavelet transform for cracks at L/16 location with a varying crack depth.

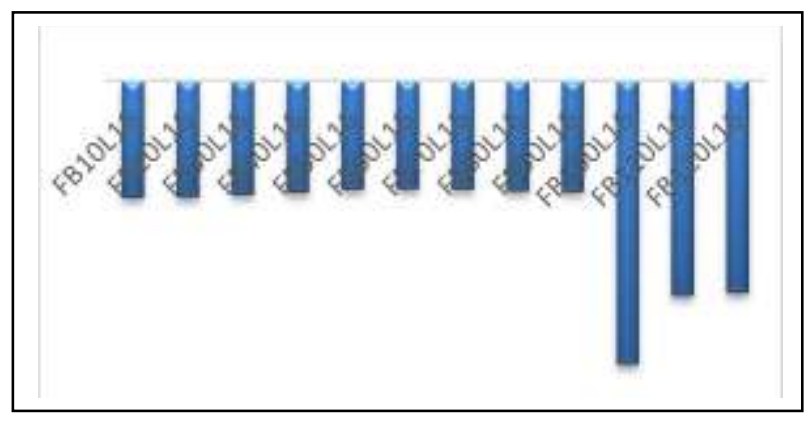

Figure 7(b) Minimum wavelet coefficient for Discrete wavelet transform for cracks at L/16 location with a varying crack depth.

It can be seen from Figure 7(a) and (b) that as the depth of the crack increases the maximum and minimum discrete wavelet coefficient does not have a definite trend of increase or decrease. Therefore, continuous wavelet coefficients are much effective in determining the depth or intensity of the crack when compared to the discrete wavelet coefficients.

\section{Conclusion}

Wavelet based methodology has an advantage of not having the knowledge of vibrational data of the undamaged structure, unless the relative intensity of the damage need to be known and in doing so continuous wavelet transform gave much effective results when compared to discrete wavelet transform. Both Continuous and Discrete wavelet transforms were able to predict the existence and location of the damage exactly. A fact that makes the wavelet based methodology easy to implement in practice is that it can be applied in the areas of expected damages only. Care should 
be taken in selecting the type and scale of the wavelet, which when chosen wrong would lead to misleading results.

\section{References}

[1] C. Surace and R. Ruotolo. Crack detection of a beam using the wavelet transform. In Proceedings of the 12th International Modal Analysis Conference, pages 1141-1147, 1994.

[2] W. J. Wang and P. D. McFadden. Application of orthogonal wavelets to early gear damage detection. Mech. Syst. Sig. Process., 9:497-507, 1995.

[3] W. J. Staszewski and G. R. Tomlinson. Application of the wavelet transform to fault detection in a spur gear. Mech. Syst. Sig. Process., 8:289-307, 1994.

[4] K. M. Liew and Q. Wang. Application of wavelet theory for crack identification in structures. J. Eng. Mech., 124:152-157, 1998.

[5] Q. Wang and X. Deng. Damage detection with spatial wavelets. Int. J. Solids Struct., 36:3443-3468, 1999.

[6] A. Al-khalidy, M. Noori, Z. Hou, R. Carmona, S. Yamamoto, A. Masuda, and A. Sone. A study of health monitoring systems of linear structures using wavelet analysis. Approximate Methods in the Design and Analysis of Pressure Vessels and Piping Components, ASME PVP, 347:49-58, 1997.

[7] Z. Hou, M. Noori, and R. S. Amand. Wavelet-based approach for structural damage detection. J. Eng. Mech., 126(7):677-683, 2000.

[8] A. Hera and Z. Hou. Application of wavelet approach for ASCE structural health monitoring benchmark studies. J. Eng. Mech., 130(1):96-104, 2004.

\section{About Author (s):}

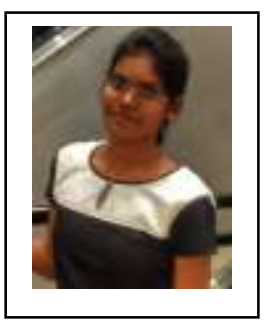

DivyaVani B, Assistant Professor, Civil Engineering Department, M.Tech in Computer Aided Structural Engineering, IIIT Hyderabad, Have published 7 papers including Indian Geotechnical Engineering Conference on Sustainability in Geotechnical Engineering Practices and Related Urban Issue in 2016.

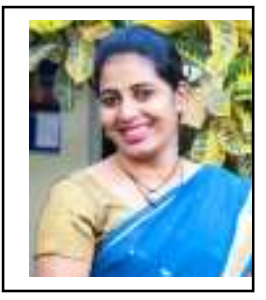

B. Prakruthi Gowd, Assistant Professor, Civil Engineering Department and Presently pursuing Ph.D in the field of Structural Health Monitoring. Gold medalist in M.Tech, Structural Engineering. The research area is Damage Detection in Structures using Vibration based Damage Detection Techniques (Wavelet Transforms, Fuzzy Logic and Artificial Neural Network).

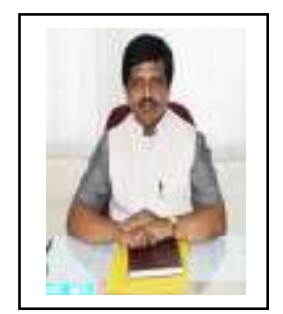

Dr. Manjunatha N. Hegde, DeanAcademic, Professor of Civil Engineering, has obtained $\mathrm{PhD}$ degree in Civil Engineering from Indian Institute of Science (IISc) and has 31 years of teaching and/ research experience. His research area includes FEM in Stochastic Structural Dynamics \& Earthquake Engineering, Fibre Reinforced Concrete, System Identification, Damage Assessment and health Monitoring of Civil Infrastructures, and Life Cycle Energy Cost of Buildings. $\mathrm{He}$ is the member of Professional bodies like IEI, ISTE, ISET, ICI, ACCE (I), and INSTRUCT. He is the Member of Board of Studies and/ Examinations of Autonomous Engineering Colleges under VTU. 